\title{
Rodrigo Kamimura
}

Arquiteto e urbanista, doutorando pelo Instituto de Arquitetura e Urbanismo de São Carlos, Universidade de São Paulo (IAU-USP), Av. Trabalhador São-Carlense, 400, Centro, CEP 13566-590, São Carlos, SP, (21) 98229-0350, rodrigokamimura@yahoo.com.br

Nenhuma conclusão é inabalável, nenhuma passagem é rígida. (FERRO; LEFÈVRE, 2006, p. 36)

proveitamos a vinda de Sérgio Ferro ao Brasil para a realização desta entrevista, em outubro de 2012. O motivo da vinda de Sérgio foi a realização da disciplina "Apontamentos sobre história da arte e da arquitetura: Renascimento, Modernismo e Brasil", promovida pelo Instituto de Arquitetura e Urbanismo de São Carlos da Universidade de São Paulo (IAU/USP). Na ocasião, o arquiteto, pintor e professor pôde discorrer sobre temas pertinentes à pintura e à arquitetura, desde o Renascimento italiano, passando pelo modernismo, até o período contemporâneo. A perspectiva de Sérgio é clara: analisar a obra de arte a partir das complexas relações sociais que envolvem o seu processo de produção, a divisão social do trabalho, e também o caráter emancipador inerente à atividade artística, manifestação suprema do trabalho livre.

Nesta entrevista, voltamos nosso interesse para as questões históricas envolvendo arquitetura, política e sociedade durante a década de 1960 no Brasil - mais especificamente na cidade de São Paulo ${ }^{1}$. Dentro deste contexto, a atuação de Ferro é rica em significados, fomentando um intrigante questionamento do papel desempenhado pelo arquiteto e urbanista em meio à particular conjuntura política e econômica pela qual passava o país, às voltas com o fatídico golpe de 1964.

Formado em 1961 pela FAU/USP, Ferro, junto aos colegas de faculdade Rodrigo Lefèvre e Flávio Império, foi responsável pela produção arquitetônica que ficaria posteriormente conhecida pela alcunha de "Arquitetura Nova" - título do texto que Ferro escreveria posteriormente para a revista Teoria e Prática, em 1967, e referência evidente ao vanguardismo do "Cinema Novo". Ainda durante a faculdade, Ferro e Lefèvre já recebiam as primeiras encomendas profissionais, tendo inclusive elaborado projetos para a nova capital federal, como os edifícios "Goiás" e "São Paulo" (1960). Anos mais tarde, em 1965, Ferro, Lefèvre e Império estabelecem escritório próprio na Rua Marquês de Paranaguá, lugar que se torna ponto de encontro de artistas, intelectuais e futuros militantes.

Trabalhando e escrevendo ora individualmente, ora em grupo, o trio busca, através de sua obra, propor não só uma reflexão, mas também um projeto de ação, com relação aos caminhos do desenvolvimento nacional que se encontram em aberto naquele momento. Como um primeiro exemplo, nesse sentido, podemos citar o projeto de Ferro para a residência do historiador Boris Fausto, construída em 1961 no Butantã. A montagem de peças leves préfabricadas adaptadas a uma modulação estrutural rígida demonstra a preocupação com a racionalização da construção e a utilização de uma linguagem simples e funcional. Já a residência de Bernardo Issler, do mesmo ano, revela uma preocupação que viria a ser central principalmente para Ferro e Lefèvre: a otimização de sistemas construtivos de baixa tecnologia com emprego de mão-de-obra intensiva. A partir destas e de outras experiências, Ferro, Lefèvre e Império puderam empreender um rigoroso e contínuo questionamento que extravaza os limites tradicionais da prática arquitetônica, ao confrontar as violentas condições de exploração presentes nos canteiros de obras, e também o papelchave desempenhado pela figura do arquiteto - e a da própria arquitetura como disciplina - para a manutenção e legitimação da dominação, da divisão 


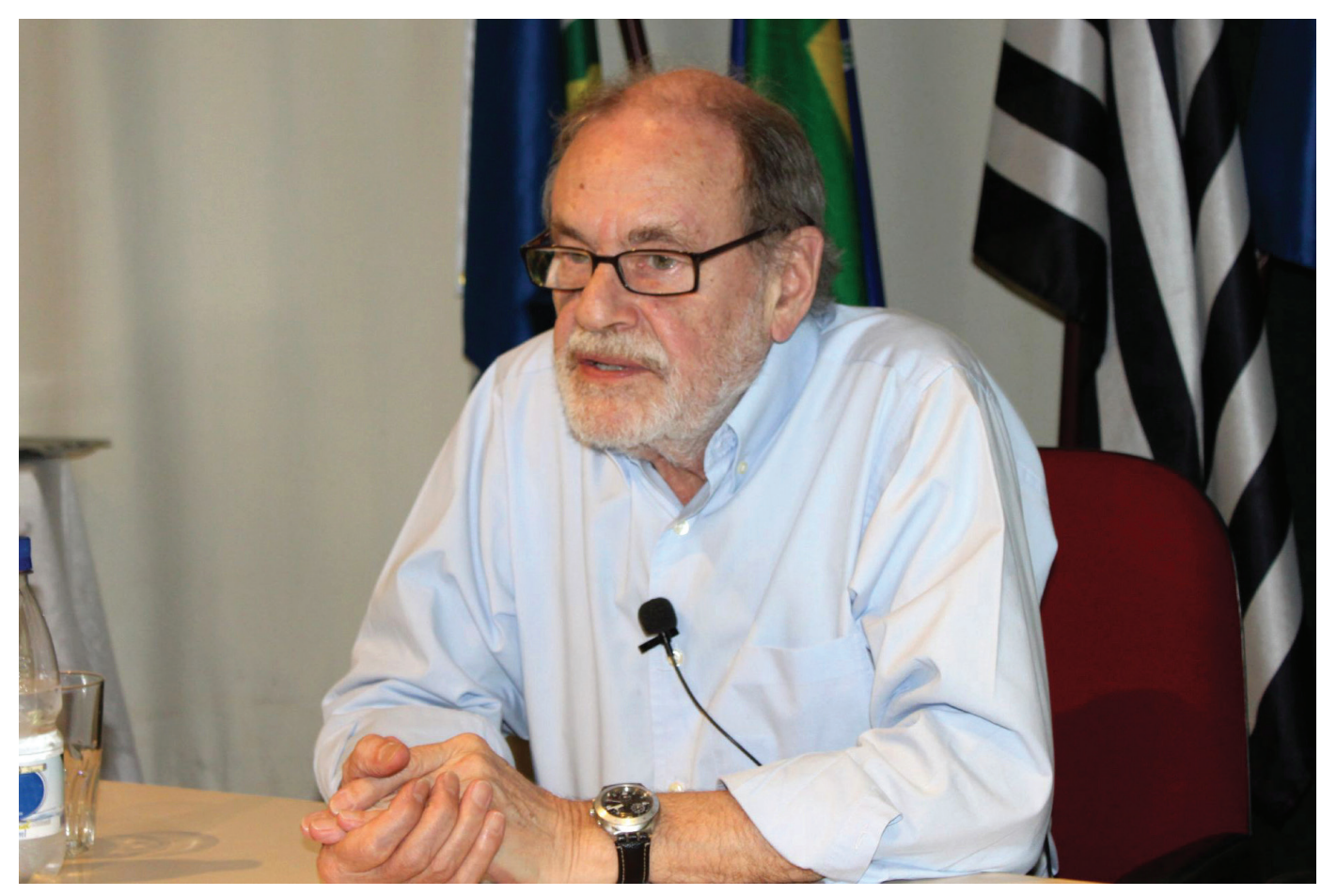

Figura 1: Sérgio Ferro no IAU/USP, outubro de 2012. Fonte: foto de Paulo Ceneviva, Laboratório Midimagem, IAU-USP. social do trabalho e da separação entre trabalho intelectual e trabalho manual.

Como resultado, desenvolveram seus projetos a partir de indagações éticas, funcionais e construtivas, mais do que meramente formais. O sistema de abóbodas de tijolos, por exemplo - aprimorado em diversas obras realizadas pelo grupo -, maximizava o aproveitamento do concreto como material, explorava a lógica de distribuição e solicitação dos esforços na estrutura, contribuía para a organização das etapas de trabalho e abrigava obra, operários e materiais com maior praticidade. Mais do que isso, Ferro, Lefèvre e Império mantiveram o seu foco sobre as relações de produção no canteiro, valorizando a horizontalidade do diálogo entre arquitetos e operários, o trabalho colaborativo, a interlocução entre conhecimentos técnico e prático.

Concomitantemente à produção arquitetônica, os três arquitetos manifestam-se também textualmente, como no artigo Proposta inicial para um debate, escrito por Ferro e Lefèvre para o caderno Encontros GFAU, em 1963, e na coletânea de textos e projetos publicada pela revista Acrópole, em 1965, já com a participação de Império. Nestes escritos, enfatizam a necessidade da atividade crítica informando constantemente a praxis arquitetônica, que deveria , analogamente, subsidiar a constante reavaliação das opções tomadas. "É com a consciência clara desta situação-no-conflito que devemos atuar. A lógica absoluta não pode ser nossa característica: mais que soluções reais, são problemas que levantamos" (FERRO; LEFÈVRE, 2006, p. 34).

Sob os ventos reformistas do pré-64 - e mesmo ainda em meio à nebulosa situação do pós-golpe -, as experiências realizadas para clientes particulares, constituíram-se como arquitetura de laboratório (nas palavras do próprio Sérgio à época): visavam, a partir de soluções específicas, mostrar-se como propostas concretas maiores em consonância com uma "poética da economia", "numa atitude de espera e estímulo de transformações sociais profundas" (FERRO; IMPÉRIO; LEFÈVRE, 2006, p. 39). Com o estreitamento político do final daquela década, no entanto, Ferro e Império acabaram por afastar-se progressivamente da prática arquitetônica tal qual a haviam ensaiado, legado ao qual Lefèvre pôde ainda esboçar certa continuidade ao longo dos anos setenta; sendo que Ferro e Lefèvre, particularmente, participaram ainda em movimentos de resistência armada contra o regime militar, sendo posteriormente presos e afastados da docência na 
FAU/USP. Em 1971, Sérgio Ferro se exila na França, onde vive até hoje.

Para elaborar o questionário desta entrevista, inserimos nossas preocupações na conjuntura política e cultural do imediato pós-Brasília, e dos importantes fatores que puderam ser extraídos desta experiência que diz respeito não apenas à cultura nacional, mas à arquitetura moderna como um todo. O gigantismo da nova capital e a voracidade das transformações sociais decorrentes daquele momento de aceleração econômica - os "50 anos em 5" de Juscelino Kubitscheck - mostraram, através da experiência direta, as graves consequências sociais e urbanas que deveriam passar a integrar a pauta dos debates promovidos por arquitetos e urbanistas.

Mas há, também, outra condicionante (que não deixa de estar relacionada à anterior): um crescente sentimento de crise institucional em largo espectro, que repercute tanto na Europa quanto em terras americanas, relacionados à série de acontecimentos do segundo pós-guerra. Crise que envolve fenômenos tão díspares quanto as Revoluções Chinesa (1949) e Cubana (1959), o existencialismo e o estruturalismo europeus, ou ainda a realização do $20^{\circ}$ Congresso do Partido Comunista da URSS (1956). E envolve também uma profunda revisão crítica do marxismo internacional e, no plano local, polêmicas internas ao Partido Comunista Brasileiro (PCB).

Finalmente, ressaltamos também a discussão considerando-se o confuso processo histórico de
1964: o autoritarismo, se não interrompe, à primeira vista, os processos culturais em curso, pode alterar o sinal que os precede: o quanto de "democrático" ou "progressista" pode haver no desenvolvimento das forças produtivas per se, ou o quão "libertário" pode ser de fato a coletivização dos mesmos, é algo que ainda demanda reflexão. O que se sugere é que há, aí, o embaraço e a apropriação de significados atribuídos a diferentes opções políticas, da direita à esquerda, de coloração nacionalista ou não; um imbróglio que podemos facilmente identificar na conjuntura histórica imediata do pós-golpe, e em seu subsequente e gradativo aprofundamento.

As "metades" da década de 1960 parecem, assim, se complementar: na primeira, pré-64, as opções se mostram com maior transparência, ao contrário do embaralhamento que perpassa a segunda. 0 que nos remete, voltando ao nosso enfoque, ao problema da profissão do arquiteto e urbanista, sua relação intrínseca com o desenvolvimento social, sua inserção no mercado, a postura diante das encomendas que the são feitas. Remete ao difícil casamento entre o plano político e o plano cultural, à sua própria conformação e entrelaçamento contraditórios, às difíceis opções tomadas por seus atores, e suas decorrências.

É nesse sentido que consideramos de fundamental importância o depoimento de Sérgio Ferro, cuja obra teórica e prática contribui para que possamos lançar um olhar mais atento sobre este momento singular da arquitetura brasileira. 